Letter

\title{
An Analysis of a Compact Label-Free Guiding-Wave Biosensor Based on a Semiconductor-Clad Dielectric Strip Waveguide
}

\author{
Carlos Angulo Barrios 1,2 \\ 1 Institute for Optoelectronic Systems and Microtechnology (ISOM), ETSI Telecomunicación, \\ Universidad Politécnica de Madrid, Ciudad Universitaria s/n, 28040 Madrid, Spain; \\ carlos.angulo.barrios@upm.es \\ 2 Department of Photonics and Bioengineering (TFB), ETSI Telecomunicación, \\ Universidad Politécnica de Madrid, Ciudad Universitaria s/n, 28040 Madrid, Spain
}

Received: 15 May 2020; Accepted: 12 June 2020; Published: 14 June 2020

\begin{abstract}
In this paper, a compact, integrated, semiconductor-clad strip waveguide label-free biosensor is proposed and analyzed. The device is based on CMOS-compatible materials such as amorphous-Si and silicon oxynitride. The optical sensor performance has been modeled by a three-dimensional beam propagation method. The simulations indicate that a $20-\mu \mathrm{m}$-long device can exhibit a surface limit of detection of $3 \mathrm{ng} / \mathrm{cm}^{2}$ for avidin molecules in aqueous solution. The sensor performance compares well to those displayed by other photonic biosensors with much larger footprints. The fabrication tolerances have been also studied in order to analyze the feasibility of the practical implementation of the biosensor.
\end{abstract}

Keywords: optical biosensor; photonic modeling; waveguide; integrated optics

\section{Introduction}

Integrated optics-based biosensors offer a number of remarkable features such as their small size, high-scale integration, high sensitivity, robustness and potential for multiplexed detection that make them ideal for lab-on-chip integration [1-3]. These compact devices are particularly well-suited for label-free detection schemes since they are able to measure small refractive index changes produced by the recognition of unlabeled analytes [4]. The use of Si-based materials provides additional and important advantages, like the possibility of employing highly developed fabrication techniques based on the CMOS technology and integration with advanced readout electronics on the same chip. Thus, a variety of Si-based integrated photonic biosensors have been reported in the literature, including Mach-Zehnder [5-8] and Young [9,10] interferometers, bimodal waveguides [11], microcavities [12-15] and photonic crystals $[16,17]$.

Semiconductor and metal-clad optical waveguides allow for the modulation of the properties of propagating light due to coupling between the lossless modes of the dielectric waveguide and the lossy optical modes supported by the thin cladding layer [18-21]. This coupling depends on the thickness and refractive index of the cladding layer, as well as on the refractive index of the surrounding medium, which makes this type of guided-wave structures suitable for refractometric (bio)sensing [22-28]. Compared to metal-clad configurations, the use of a semiconductor layer cladding allows for the use of both transverse electric (TE) (the electric field has no component in the direction of propagation) and transverse magnetic (TM) (the magnetic field has no component in the direction of propagation) polarization modes $[18,19]$ and offers the possibility of obtaining higher refractive index sensitivities [25]. However, despite a semiconductor-clad waveguide is highly amenable to be 
integrated on planar substrates, scarce work has been devoted to study this prospect for, for example, lab-on-chip biosensing microsystems; the vast majority of semiconductor-clad waveguide biosensors have been demonstrated using optical fibers [25-28].

In this work, an integrated, semiconductor-clad strip waveguide biosensor based on CMOS-compatible materials is proposed and analyzed. The device optical performance, sensitivity to both bulk refractive index and adlayer (biofilm) thickness, and tolerance to dimensional and material parameter variations have been studied through three-dimensional numerical modeling. Simulations indicate that the proposed device shows good sensing characteristics to be used as a compact photonic label-free biosensor, and provide important information concerning its actual implementation.

\section{Device Configuration and Modeling}

Figure $1 \mathrm{a}, \mathrm{b}$ show a perspective and cross-section schematics, respectively, of the proposed guided-wave optical biosensor. It consists of a thin semiconductor layer (cladding) deposited on the top surface of a lossless dielectric strip waveguide on a silicon dioxide $\left(\mathrm{SiO}_{2}\right)$ substrate. The width of both the cladding layer and the strip waveguide is $\mathrm{w}=1 \mu \mathrm{m}$. The semiconductor cladding layer thickness equals $t_{c}$ and the height of the strip waveguide is $h=1 \mu \mathrm{m}$. The length of the semiconductor cladding layer is denoted as $\mathrm{z}_{\mathrm{c}}$. The cladding and waveguide materials are assumed to be amorphous silicon (a-Si) and silicon oxynitride ( $\mathrm{SiON})$, respectively. The refractive indices of a-Si, SiON and $\mathrm{SiO}_{2}$ at a free-space wavelength of $632.8 \mathrm{~nm}$ (operation wavelength) have been considered to be $\mathrm{n}_{\mathrm{Si}}=4.1-\mathrm{j} 0.21$ [29], $\mathrm{n}_{\mathrm{wg}}=1.52$ [30] and $\mathrm{n}_{\text {sub }}=1.46$, respectively. The upper cover region (bulk) has a refractive index of $n_{b}$. Both the upper cover and substrate regions are assumed to be semi-infinite in extent. For the biosensing analysis, a uniform protein film (biofilm) of thickness $t_{\text {bio, }}$ width $w$, length $\mathrm{z}_{\mathrm{c}}$, and refractive index $\mathrm{n}_{\text {bio }}=1.41$ [31] has been assumed to be adhered on the semiconductor cladding layer in an aqueous medium $\left(\mathrm{n}_{\mathrm{b}}=1.33\right)$.

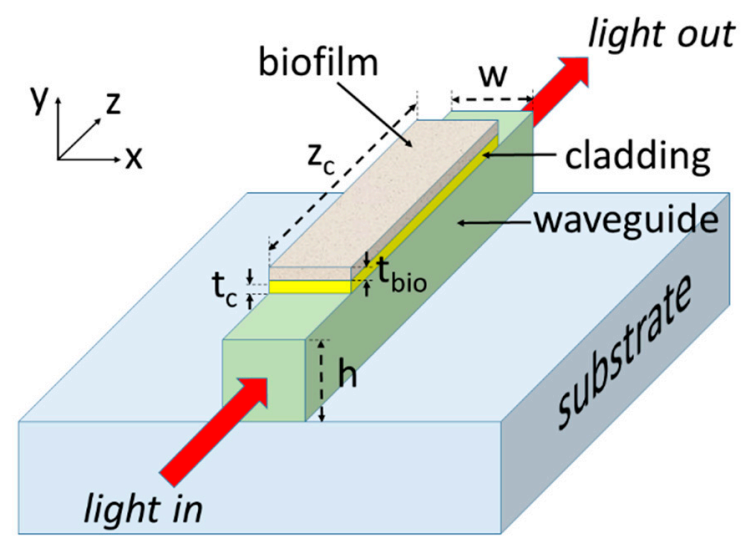

(a)

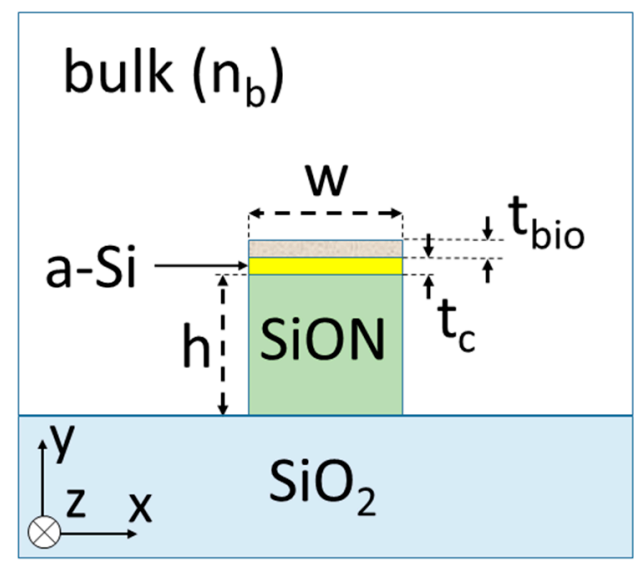

(b)

Figure 1. Perspective (a) and cross-sectional (b) schematics of a semiconductor-clad dielectric strip waveguide biosensor. The cladding, waveguide and substrate are assumed to be amorphous-Si (a-Si), silicon oxynitride ( $\mathrm{SiON}$ ) and $\mathrm{SiO}_{2}$, respectively. The biofilm consists of a layer of biomolecules such as proteins.

The bio-sensitive area of the optical device is the top surface of the semiconductor cladding layer, where biomolecule receptors (e.g., antibodies) can be immobilized or adsorbed (biofilm in Figure 1a). Light, at an operating wavelength of $632.8 \mathrm{~nm}$, is injected at the input port of the waveguide and the optical power exiting the output port is used as the sensor response. Analyte recognition by the immobilized bioreceptors produces a change in the biofilm thickness and, therefore, in the local refractive index over the cladding layer, which affects the optical power coupling between the lossy 
semiconductor layer and the lossless dielectric waveguide. This is displayed as an optical power variation at the output of the waveguide.

A three-dimensional beam propagation method (BPM) [32] was used for the calculation of the modal-field profile and optical power propagating along the waveguide ( $z$-axis). The computational grid and step sizes along $\mathrm{x}, \mathrm{y}$ and $\mathrm{z}$ were $\Delta \mathrm{x}=50 \mathrm{~nm}, \Delta \mathrm{y}=0.5 \mathrm{~nm}$ and $\Delta \mathrm{z}=50 \mathrm{~nm}$, respectively. Transparent boundary conditions in the computational domain were used in the simulations.

\section{Results}

The bare dielectric strip waveguide configuration (that is, $t_{c}=t_{b i o}=0$ ) exhibits single mode operation for both quasi-TE and quasi-TM polarization modes when the upper cover is assumed to be water $\left(n_{b}=1.33\right)$. Figure 2 shows the corresponding optical mode-field profiles for the quasi-TE (Figure 2a) and quasi-TM (Figure 2b) fundamental modes. The calculated effective refractive indices were 1.4811 and 1.4818, respectively. Thus, the launched (input) fields used in the BPM simulations of the device for $t_{c} \geq 0$ were the fundamental modes of the bare dielectric waveguide for the corresponding polarization.

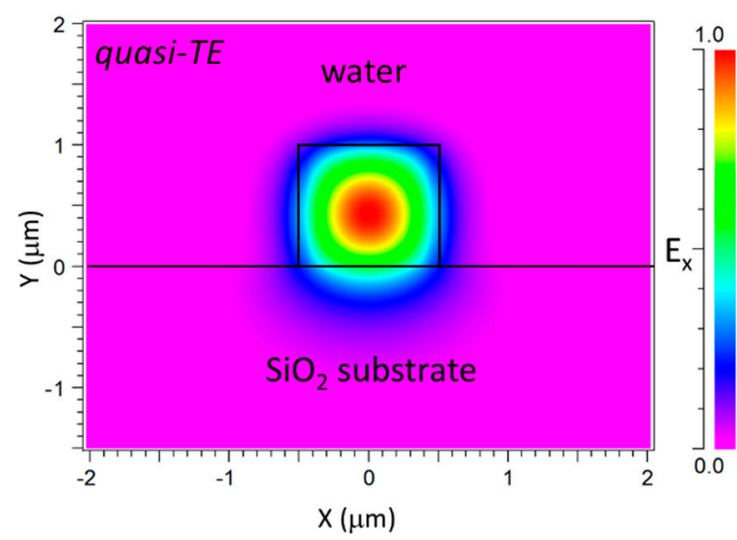

(a)

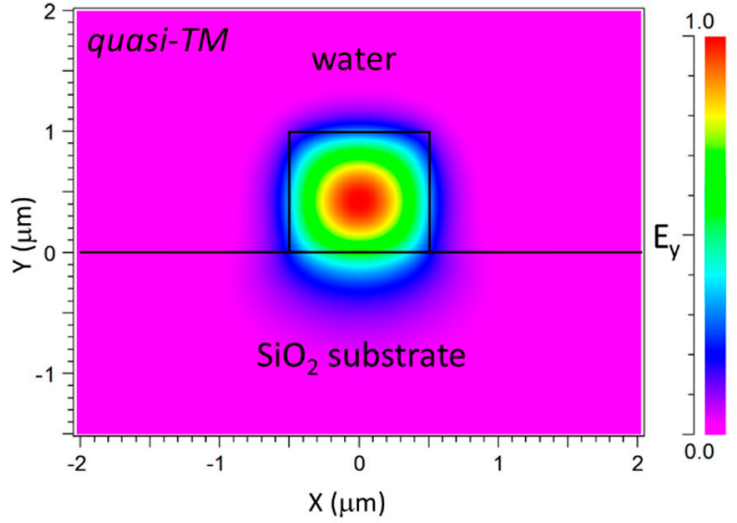

(b)

Figure 2. Transverse electric field profiles of the quasi-transverse electric (TE) (a) and quasi-transverse magnetic (TM) (b) fundamental optical modes in a bare dielectric $(\mathrm{SiON})$ waveguide $\left(\mathrm{t}_{\mathrm{c}}=\mathrm{t}_{\mathrm{bio}}=0\right)$ at $\lambda=632.8 \mathrm{~nm}$ in an aqueous medium. $\mathrm{E}_{\mathrm{x}}(\mathrm{a})$ and $\mathrm{E}_{\mathrm{y}}(\mathrm{b})$ are the electric field components along the $x$-axis and $y$-axis, respectively.

Figure 3 plots the calculated output power $\left(\mathrm{P}_{\mathrm{o}}\right)$, normalized to the input power, of the studied guided-wave device as a function of the semiconductor layer thickness $t_{c}$ for quasi-TE (black line) and quasi-TM (red line) polarizations for $n_{b}=1.33, z_{c}=20 \mu \mathrm{m}$ and $t_{b i o}=0$. Quasi-TE and quasi-TM polarizations exhibit different behaviors, indicating different guide-cladding interactions. This is a consequence of the different sets of boundary conditions for each polarization [18,19]. Several transmission dips are observed for both polarizations in Figure 3. These output power transmission minima (attenuation maxima) arise from the periodic coupling effect between the lossless mode of the dielectric waveguide and the lossy mode of the thin semiconductor cladding layer $[18,19]$.

BPM simulations revealed that variations in the bulk refractive index $n_{b}$ leads to shifts of the transmission dips along the $t_{c}$ axis, implying that the output power is sensitive to the bulk refractive index for particular $t_{c}$ values. Figure 4 shows the relative output power variation $\left(\Delta P / P_{o, w}\right)$, where $P_{o, w}$ is the normalized output power for $n_{b}=1.33$, for quasi-TE (Figure $4 a$ ) and quasi-TM (Figure $4 b$ ) polarizations, and different $n_{b}$ variations $\left(\Delta n_{b}\right)$ in the $t_{c}$ ranges where $\left(\Delta P / P_{o, w}\right)$ is largest. It is seen that, for quasi-TE mode, the maximum relative power variation occurs for $\mathrm{t}_{\mathrm{c}}=6.5 \mathrm{~nm}$ for all considered $\Delta \mathrm{n}_{\mathrm{b}}$ values, whereas, for quasi-TM polarization, the corresponding $t_{c}$ value depends on the bulk refractive index change, and varies between $121 \mathrm{~nm}\left(\Delta \mathrm{n}_{\mathrm{b}}=0.01\right)$ and $118.5 \mathrm{~nm}\left(\Delta \mathrm{n}_{\mathrm{b}}=0.05\right)$. It should be noted that the peaks in Figure 4a have larger amplitudes and are sharper than the corresponding curves in 
Figure $4 b$, indicating that the quasi-TE operation mode is more sensitive to both $n_{b}$ and $t_{c}$ variations than the quasi-TM polarization mode.

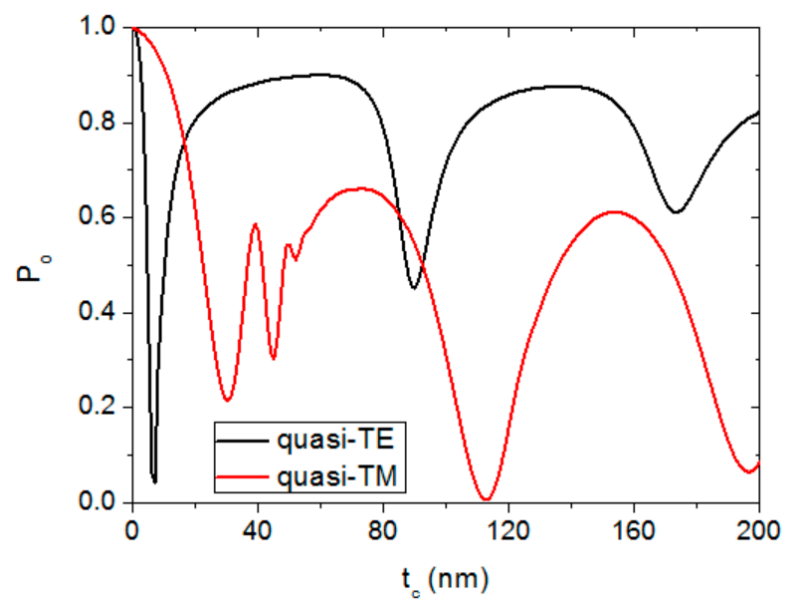

Figure 3. Normalized power at the output $\left(\mathrm{P}_{\mathrm{o}}\right)$ of a $20-\mu \mathrm{m}$-long a-Si-clad SiON strip waveguide as a function of the semiconductor thickness value for quasi-TE (black line) and quasi-TM (red line) polarizations. $\mathrm{n}_{\mathrm{b}}=1.33$ and $\mathrm{t}_{\mathrm{bio}}=0$.

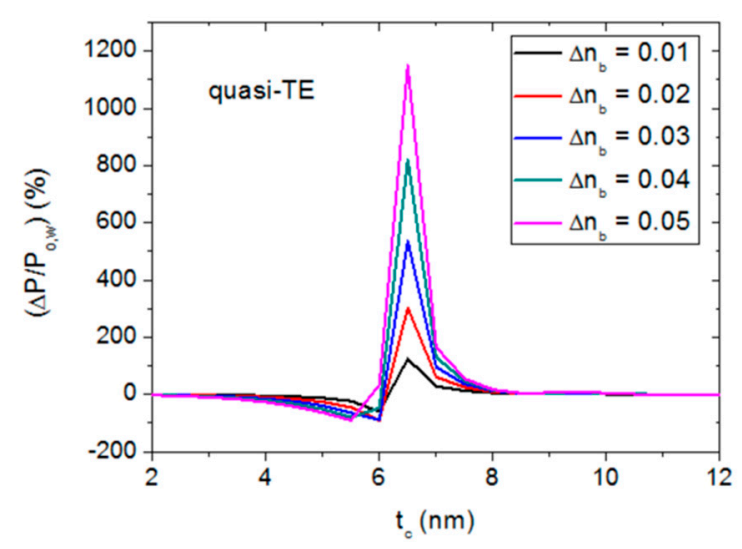

(a)

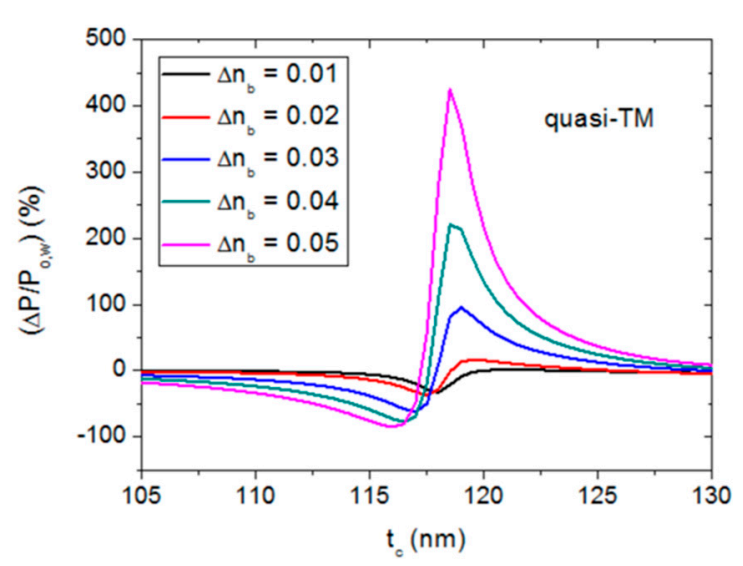

(b)

Figure 4. Relative power variation in a $20-\mu \mathrm{m}$-long semiconductor-clad dielectric strip waveguide as a function of the semiconductor thickness $\left(t_{c}\right)$ for different bulk refractive index variations $\left(\Delta n_{b}\right)$ with respect to $\mathrm{n}_{\mathrm{b}}=1.33$, for quasi-TE $(\mathbf{a})$ and quasi-TM $(\mathbf{b})$ polarizations.

Figure 5 shows the effect of the semiconductor layer length, $z_{c}$, on the relative output power variation for a particular bulk refractive index variation $\left(\Delta \mathrm{n}_{\mathrm{b}}=0.05\right)$ for quasi-TE (Figure 5a) and quasi-TM (Figure $5 b$ ) polarizations. In both cases, the maximum relative power values occur for $\mathrm{z}_{\mathrm{c}}=20 \mu \mathrm{m}$. Therefore, hereafter the length of the semiconductor layer will be assumed to be $20 \mu \mathrm{m}$ for both quasi-TE and quasi-TM operation modes, and, according to Figure 4, the thickness of the semiconductor cladding layer will be $6.5 \mathrm{~nm}$ and $118 \mathrm{~nm}$ for quasi-TE and quasi-TM polarizations, respectively. 


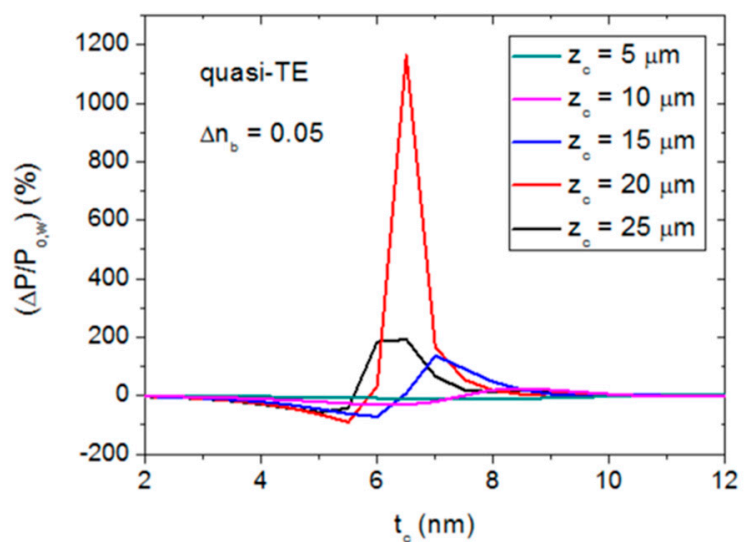

(a)

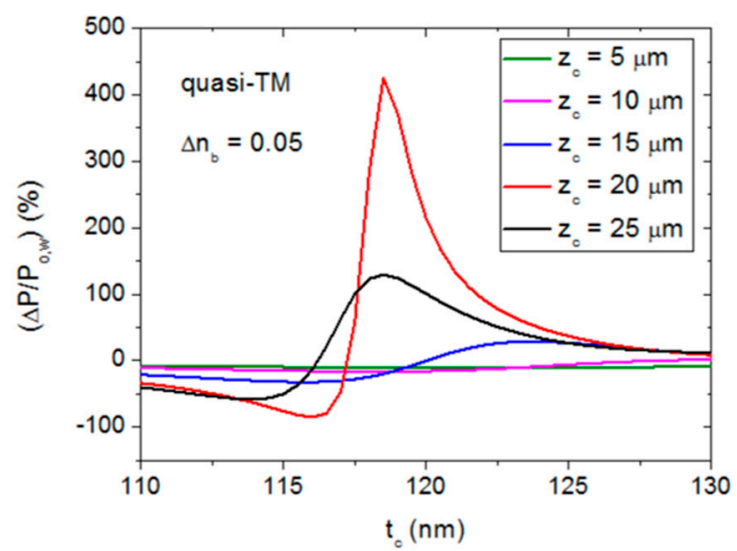

(b)

Figure 5. Relative power variation in the considered semiconductor-clad dielectric strip waveguide configuration as a function of the semiconductor thickness $\left(t_{c}\right)$ for a bulk refractive index variation $\left(\Delta \mathrm{n}_{\mathrm{b}}\right)$ of $0.05(1.38-1.33)$ and different semiconductor layer lengths $\left(\mathrm{z}_{\mathrm{c}}\right)$ for quasi-TE $(\mathbf{a})$ and quasi-TM (b) polarizations.

\subsection{Bulk Sensitivity}

Intensity-based refractive index optical sensors typically use as a figure-of-merit the relative power (or intensity) bulk sensitivity defined as [33-35]:

$$
S_{I, b}=\frac{1}{P_{o}}\left(\frac{d P_{o}}{d n_{b}}\right),
$$

Figure 6a illustrates the calculated sensor response for quasi-TE polarization (black square dots). It is seen that $P_{o}$ increases monotonically in a slightly non-linear fashion as $n_{b}$ increases. This leads to a positive and increasing value of the sensor response derivative. However, $\mathrm{P}_{\mathrm{O}}$ increases faster with $n_{b}$ than the derivative does, and counteracts the gain effect of the latter on $S_{I, b}$. The resulting consequence is a bulk sensitivity value that depends on the $n_{b}$ value as shown in Figure $6 \mathrm{~b}$ (black square dots). For the calculation of $S_{I, b}$ from the data of Figure $6 a$, the derivative of $P_{o}$ at the $i$-th point was computed as $\left(\mathrm{P}_{\mathrm{o}(\mathrm{i}+1)}-\mathrm{P}_{\mathrm{o}(\mathrm{i}-1)}\right) /\left(\mathrm{n}_{\mathrm{b}(\mathrm{i}+1)}-\mathrm{n}_{\mathrm{b}(\mathrm{i}-1)}\right)$, and the derivatives for the first $(\mathrm{i}=1)$ and last $(\mathrm{i}=6)$ points were calculated as $\left(\mathrm{P}_{\mathrm{o} 2}-\mathrm{P}_{\mathrm{o} 1}\right) /\left(\mathrm{n}_{\mathrm{b} 2}-\mathrm{n}_{\mathrm{b} 1}\right)$ and $\left(\mathrm{P}_{\mathrm{o} 6}-\mathrm{P}_{\mathrm{o} 5}\right) /\left(\mathrm{n}_{\mathrm{b} 6}-\mathrm{n}_{\mathrm{b} 5}\right)$, respectively. It is seen, in Figure $6 \mathrm{~b}$, that $\mathrm{S}_{\mathrm{I}, \mathrm{b}}$ decreases monotonically as $\mathrm{n}_{\mathrm{b}}$ increases, and exhibits a maximum value of $12,372 \% /$ RIU for $n_{b}=1.33$. Quasi-TE operation is therefore particularly suitable for refractive index sensing of diluted aqueous solutions. Assuming a minimum detectable intensity difference of $1 \%$, a bulk refractive index resolution of $8 \times 10^{-5}$ RIU [ $=1 \% / 12,372(\% /$ RIU)] should be attainable. For the sake of comparison, Table 1 shows the intensity bulk sensitivity, limit of detection (LOD), product $\mathrm{LOD} \times \mathrm{L}_{\text {sens }}$, where $\mathrm{L}_{\text {sens }}$ is the length of the sensing region, and footprint of relevant Si-based planar refractive index optical sensors reported in the literature. It is seen that the device analyzed in this work exhibits better sensitivity than those based on free-space optical interrogation [34-36]. Optical sensors based on integrated-optics [8,11] present smaller LODs but at the expense of a long sensing region. In fact, the product $\mathrm{LOD} \times \mathrm{L}_{\text {sens }}$, which is a convenient figure of merit for these type of sensors, of the studied device is similar or even better (smaller) than those of the other integrated guided-wave devices, while offering a footprint five orders of magnitude smaller. The latter is an important advantage for large-scale integration on a single chip.

The sensor response for quasi-TM polarization is also shown in Figure 6a (red circular dots). In this case, the response is clearly non-linear and non-monotonic. This leads to a magnitude and sign $\mathrm{n}_{\mathrm{b}}$-dependent behaviour of the bulk sensitivity, as shown in Figure $6 \mathrm{~b}$ (red circular dots). The maximum sensitivity, $6456 \% / \mathrm{RIU}$, is obtained for $\mathrm{n}_{\mathrm{b}}=1.37$. Thus, the quasi-TM operation of the sensor could be useful for testing liquids other than aqueous solutions, such as, for example, some organic solvents. 


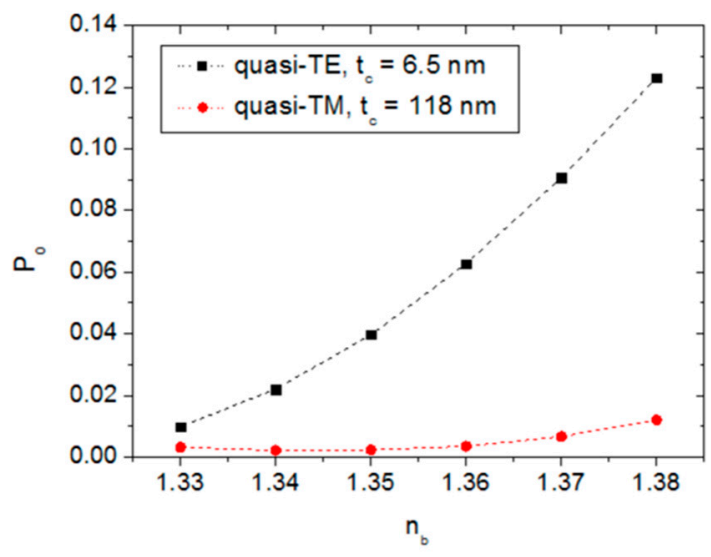

(a)

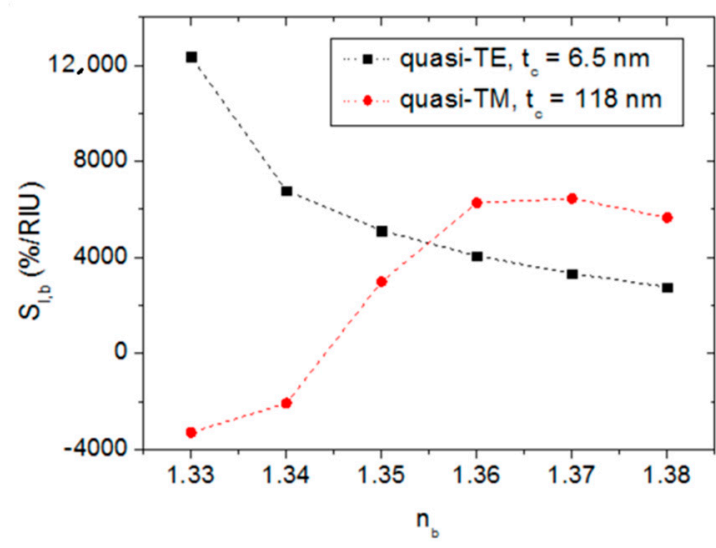

(b)

Figure 6. Sensor response (a) and bulk sensitivity (b) of the studied semiconductor-clad dielectric strip waveguide as a function of the bulk refractive index for quasi-TE (black square dots) and quasi-TM (red circular dots) polarizations. The semiconductor layer thickness values are $t_{c}=6.5 \mathrm{~nm}$ and $t_{c}=118 \mathrm{~nm}$ for quasi-TE and quasi-TM operations, respectively. Data points are connected by dashed lines for the sake of clarity.

Table 1. Si-based planar refractive index (RI) optical sensors based on intensity interrogation. Refractive index unit (RIU); Mach-Zehnder (M-Z); limit of detection (LOD); length of the sensing region $\left(\mathrm{L}_{\text {sens }}\right)$; not applicable (N/A).

\begin{tabular}{|c|c|c|c|c|}
\hline RI Sensor Configuration & Sensitivity (\%/RIU) & LOD (RIU) & LOD $\times$ L sens $($ RIU mm $)$ & Footprint $\left(\mu \mathrm{m}^{2}\right)$ \\
\hline Metasurface [34] & 4450 & $\left(2 \times 10^{-4}\right)^{\mathrm{b}}$ & $\mathrm{N} / \mathrm{A}^{\mathrm{c}}$ & $\mathrm{N} / \mathrm{A}^{\mathrm{c}}$ \\
\hline Grating/waveguide [35] & 1306 & $\left(7.6 \times 10^{-4}\right)^{b}$ & $\mathrm{~N} / \mathrm{A}^{\mathrm{c}}$ & $\mathrm{N} / \mathrm{A}^{\mathrm{c}}$ \\
\hline 1-D grating [36] & 1700 & $\left(5 \times 10^{-4}\right)^{b}$ & $\mathrm{~N} / \mathrm{A}^{\mathrm{c}}$ & $\mathrm{N} / \mathrm{A}^{\mathrm{c}}$ \\
\hline $\mathrm{M}-\mathrm{Z}$ interferometer [8] & & $5.4 \times 10^{-6}$ & $3.8 \times 10^{-5}$ & $3.4 \times 10^{6}$ \\
\hline Bimodal waveguide [11] & & $2.5 \times 10^{-7}$ & $3.7 \times 10^{-6}$ & $4.5 \times 10^{6}$ \\
\hline This work & $12,372^{\mathrm{a}}$ & $\left(8 \times 10^{-5}\right)^{b}$ & $1.6 \times 10^{-6}$ & 20 \\
\hline
\end{tabular}

${ }^{a}$ Maximum value. Sensitivity depends on the bulk refractive index. ${ }^{b}$ For a change in relative output intensity of $1 \%$. ${ }^{\mathrm{c}}$ Free-space interrogation.

\subsection{Biofilm Sensing}

Like the bulk sensitivity, the relative power (or intensity) thickness sensitivity $\mathrm{S}_{\mathrm{I}, \mathrm{t}}$ can be defined as:

$$
S_{I, t}=\frac{1}{P_{o}}\left(\frac{d P_{o}}{d t_{b i o}}\right),
$$

Figure 7a shows the sensor response as a function of the biofilm thickness for quasi-TE and quasi-TM polarizations. The corresponding thickness sensitivities are plotted in Figure $7 \mathrm{~b}$. For quasi-TE polarization (black square dots) a nearly linear response is obtained in the entire $t_{\text {bio }}$ range. The highest quasi-TE sensitivity, $\mathrm{S}_{\mathrm{I}, \mathrm{t}}=16.2 \% / \mathrm{nm}$, is achieved for $\mathrm{t}_{\text {bio }}=0 \mathrm{~nm}$. This thickness sensitivity implies that for a minimum detectable intensity difference of $1 \%$, the smallest detectable biofilm thickness would be $0.06 \mathrm{~nm}$. For a typical protein such as avidin, modeled as a sphere of diameter $5 \mathrm{~nm}$ and molecular weight of $50 \mathrm{kD}$, the surface density of a monolayer of proteins would be $254 \mathrm{ng} / \mathrm{cm}^{2}$ [37]. Thus, assuming that the sensor signal is proportional to the surface coverage, the minimum detection limit would be $3 \mathrm{ng} / \mathrm{cm}^{2}$. This value is larger than high-performance plasmonic [37] and porous $\mathrm{Si}$ [38] biosensors based on free-space and wavelength interrogation. However, it compares well to the performance of other intensity-based integrated optics Si-based biosensors as shown in Table 2. In particular, the product $\mathrm{LOD} \times \mathrm{L}_{\text {sens }}$ exhibited by the analyzed device is less than those biosensors based on integrated Mach-Zehnder [6,8] and Young interferometers [10], and its footprint is several orders of magnitude smaller. Figure $7 \mathrm{~b}$ also shows that the sensitivity for quasi-TE polarization 
decreases as the biofilm thickness increases, which is mainly a consequence of the increment of $P_{o}$ with $t_{\text {bio. }}$ Quasi-TE operation is therefore particularly well suited for detecting very thin layers of proteins deposited directly on the semiconductor cladding layer.

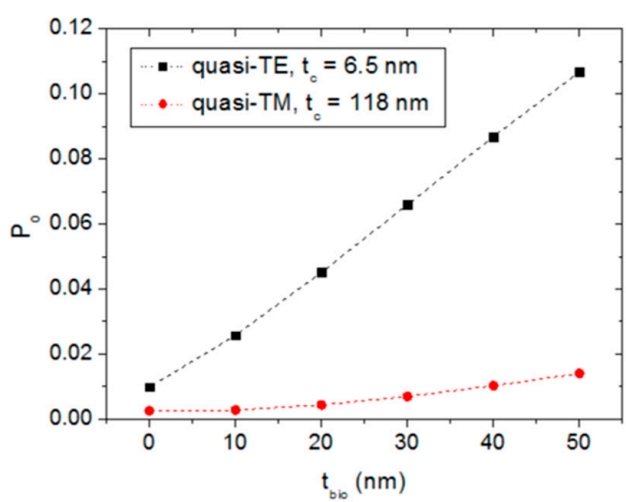

(a)

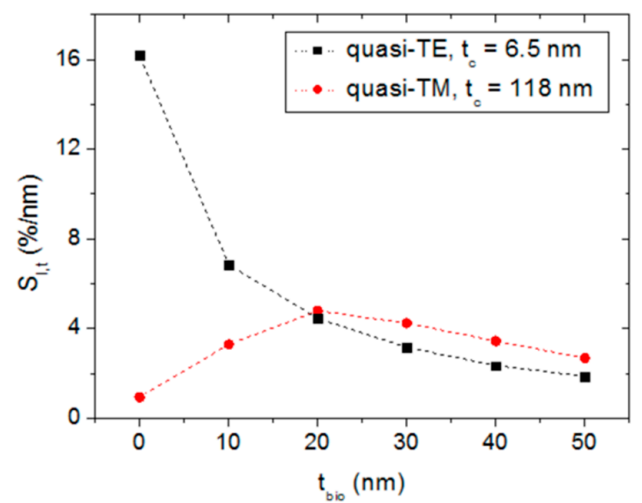

(b)

Figure 7. Sensor response (a) and thickness sensitivity (b) of the studied semiconductor-clad dielectric strip waveguide as a function of the biofilm thickness for quasi-TE (black square dots) and quasi-TM (red circular dots) polarizations. The semiconductor layer thickness values are $t_{c}=6.5 \mathrm{~nm}$ and $t_{c}=118 \mathrm{~nm}$ for quasi-TE and quasi-TM operations, respectively. Data points are connected by dashed lines for the sake of clarity.

Table 2. Si-based integrated optical biosensors based on intensity interrogation. Mach-Zehnder (M-Z); limit of detection (LOD); length of the sensing region $\left(\mathrm{L}_{\mathrm{sens}}\right)$.

\begin{tabular}{|c|c|c|c|}
\hline Biosensor Configuration & LOD $\left(\mathrm{ng} / \mathrm{cm}^{2}\right)$ & LOD $\times \mathrm{L}_{\text {sens }}\left(\mathrm{ng} \mathrm{cm}^{-2} \mathrm{~mm}\right)$ & Footprint $\left(\mu \mathrm{m}^{2}\right)$ \\
\hline M-Z interferometer [6] & 2 & 24 & $3 \times 10^{6}$ \\
\hline M-Z interferometer [8] & 0.22 & 1.54 & $3.4 \times 10^{6}$ \\
\hline Young interferometer [10] & 0.075 & 0.9 & $1.8 \times 10^{7}$ \\
\hline This work & $3^{a}$ & 0.06 & 20 \\
\hline
\end{tabular}

${ }^{\text {a }}$ Minimum value (sensitivity depends on the adlayer thickness), for a change in relative output intensity of $1 \%$.

The response for quasi-TM polarization (red circular dots) shows no variation for $\mathrm{t}_{\text {bio }}$ up to $10 \mathrm{~nm}$ and a slight linear variation for larger $t_{b i o}$ values. The quasi-TM thickness sensitivity lies between $0.9 \% / \mathrm{nm}$ and $4.8 \% / \mathrm{nm}$, exhibiting similar values to those of quasi-TE polarization for $\mathrm{t}_{\text {bio }}$ greater than $20 \mathrm{~nm}$. The low sensitivity for $t_{\text {bio }}=0(0.9 \% / \mathrm{nm})$ indicates that, for quasi-TM operation, the sensing device should contain a pre-deposited (or immobilized) biofilm of thickness equal or greater than $10 \mathrm{~nm}$ in order to function at a higher sensitivity operating point. Such a biofilm could be made up by one or several monolayers of biomolecule receptors such as antibodies.

\subsection{Material and Dimension Tolerance}

From a fabrication perspective, geometrical and material parameter deviations from the target values can always occur. An analysis of the sensitivity of the device performance to these deviations allows critical fabrication parameters to be identified, assisting the technologists in determining or developing proper processing techniques.

Since the quasi-TE polarization mode exhibits both a larger response variation and surface sensitivity than those obtained for the quasi-TM mode, only the former operation mode has been considered in this tolerance analysis. Thus, for a target device characterized by: $h=w=1 \mu \mathrm{m}$, $\mathrm{z}_{\mathrm{c}}=20 \mu \mathrm{m}, \mathrm{t}_{\mathrm{c}}=6.5 \mathrm{~nm}, \operatorname{Re}\left(\mathrm{n}_{\mathrm{Si}}\right)=4.1, \operatorname{Im}\left(\mathrm{n}_{\mathrm{Si}}\right)=0.21, \mathrm{n}_{\mathrm{wg}}=1.52$ and $\lambda=632.8 \mathrm{~nm}$, Figure 8 shows the sensor response (device output power as a function of the biofilm thickness) for individual variations in $\mathrm{h}$ (Figure 8a), w (Figure 8b), $\mathrm{z}_{\mathrm{c}}$ (Figure $\left.8 \mathrm{c}\right), \mathrm{t}_{\mathrm{c}}($ Figure $8 \mathrm{~d}), \operatorname{Re}\left(\mathrm{n}_{\mathrm{Si}}\right)($ Figure $8 \mathrm{e}), \operatorname{Im}\left(\mathrm{n}_{\mathrm{Si}}\right)($ Figure $8 \mathrm{f})$, and $\mathrm{n}_{\mathrm{wg}}$ (Figure 8g). 


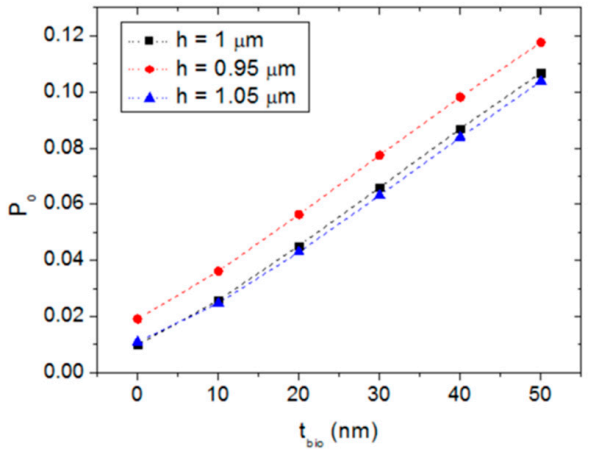

(a)

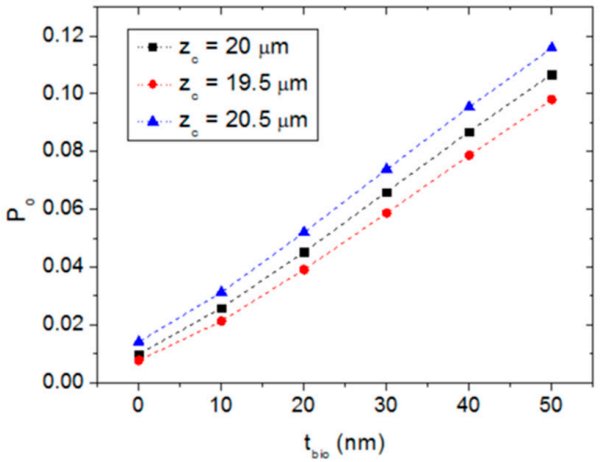

(c)

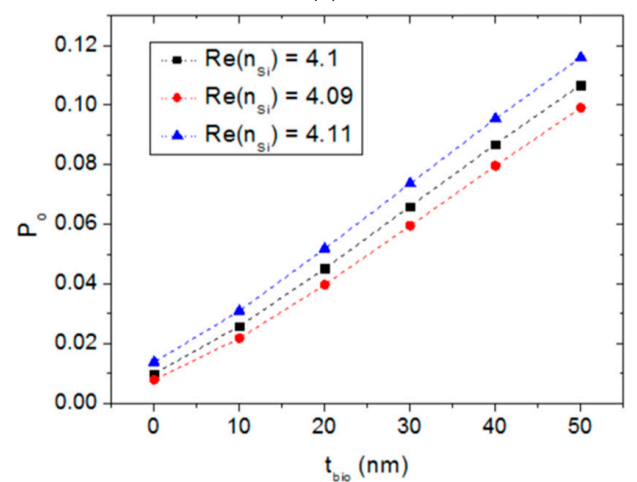

(e)

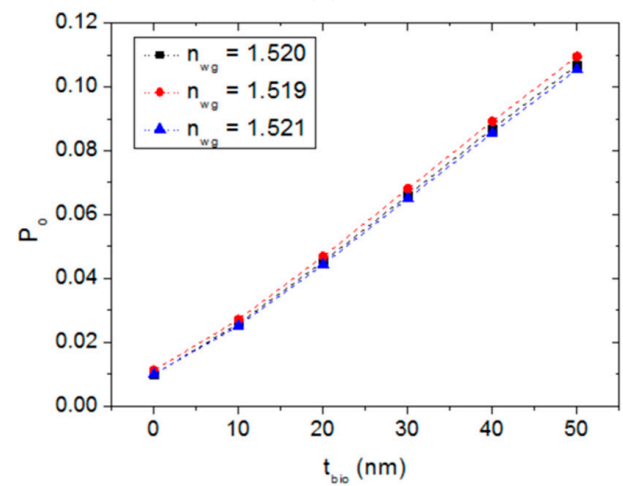

(g)

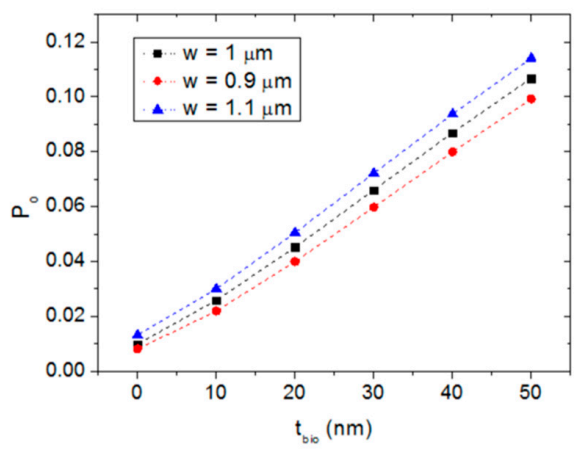

(b)

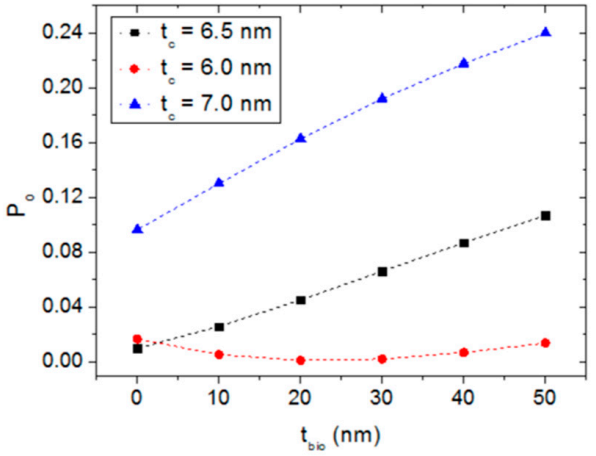

(d)

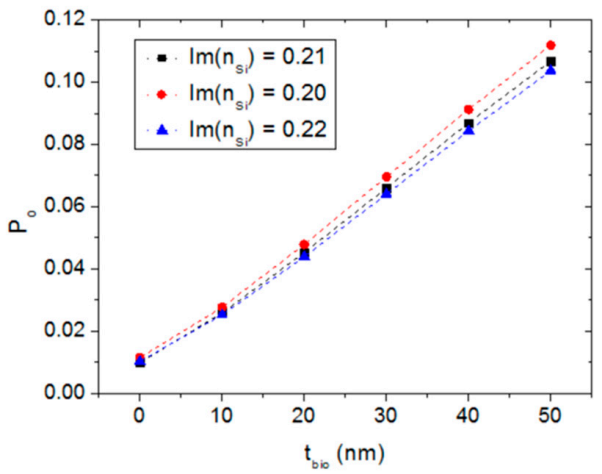

(f)

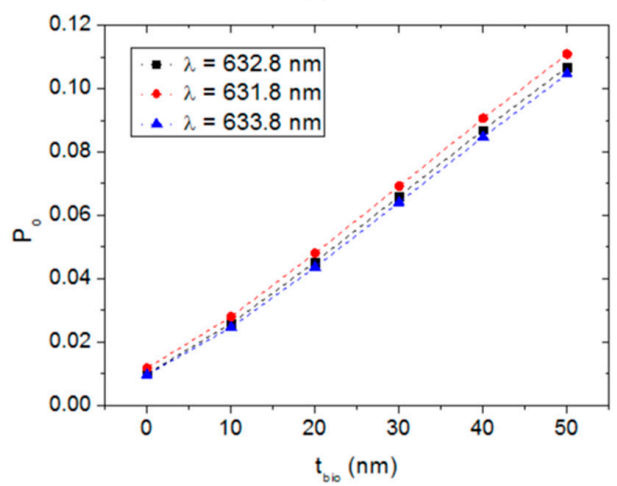

(h)

Figure 8. Normalized power at the output of a target a-Si-clad SiON strip waveguide as a function of the biofilm thickness for different dimensional and material parameter variations: (a) waveguide height variation, (b) waveguide width variation, (c) semiconductor cladding length variation, (d) semiconductor cladding thickness variation, (e) variation in the real part of the semiconductor cladding refractive index, (f) variation in the imaginary part of the semiconductor cladding refractive index, (g) SiON waveguide refractive index variation, and (h) operation wavelength variation. 
These figures reveal that the most critical fabrication parameter is the thickness of the a-Si cladding layer. Acceptable tolerances are obtained for the rest of the considered parameters. From the sensor operation point of view, it is also relevant to analyze the effect of deviations in the operating wavelength on the sensor performance. Wavelength variation can be originated by, for example, thermal fluctuations affecting the light source (laser device). Figure $8 \mathrm{~h}$ shows that a variation of \pm $1 \mathrm{~nm}$ in the operating wavelength has a negligible effect on the sensor response.

\section{Discussion}

The integrated device analyzed in this work is based on a single channel. There is no need for the Y-shape splitters used in integrated Mach-Zehnder and Young interferometer biosensors, which significantly increase the footprint and are complicated to design and fabricate. Besides, the sensor response is obtained by monitoring the waveguide output optical intensity (or power). Intensity-based read-out schemes essentially require a fixed wavelength source (typically a single wavelength laser device) and a photodetector, simplifying the overall sensing system; interrogation schemes based on wavelength shift measurement require more complex and costly equipment such as a tunable laser source or a spectrum analyzer.

The choice of silicon oxynitride for the waveguide material has been motivated by the purpose of obtaining single mode operation at the operating wavelength using micron-sized cross-sectional waveguide dimensions and Si-based materials. Waveguides with micron-sized cross sections facilitate both direct optical coupling (butt coupling) and fabrication compared to submicrometersize waveguides. SiON can be deposited by conventional chemical vapor deposition (CVD) techniques $[6,10,30]$ and, depending on composition, its refractive index can be varied between that of silicon dioxide and that of silicon nitride, offering high potential and flexibility for optical waveguide design.

The micrometer dimensions of the dielectric waveguide $(1 \mu \mathrm{m} \times 1 \mu \mathrm{m} \times 20 \mu \mathrm{m})$ allow for its fabrication using standard methods from the microelectronics industry such as CVD, photolithography and reactive ion etching (RIE). There is no need for complex and expensive nanolithographic processes. Figure 9 illustrates a schematic description of the main processing steps involved in the fabrication of the studied sensor on a Si wafer. The simulation results have indicated that the most challenging fabrication issue is the deposition of the a-Si layer, whose thickness should be controlled to the monolayer level (approximately, $0.5 \mathrm{~nm}$ ). This task can be carried out by atomic layer deposition (ALD), which is a well-known and mature technology that allows for the deposition of ultrathin films of dielectric and semiconductor materials, such as Si [39-41], with precisely controlled thickness at the atomic scale and high uniformity over large areas. Note that, unlike the difficulties of nanopatterning lateral features, very high-quality thin films can be deposited with sub-nanometer control on a substrate. Finally, the device can be converted into a biosensor by immobilizing biomolecules on the surface of the a-Si cladding film, which could be achieved by contact printing with PDMS (polydimethylsiloxane) inked with proper biomolecules [42,43].

To conclude, the performance of the modeled integrated optical biosensor, particularly for quasi-TE polarization, compares well to state-of-the-art Si-based planar optical biosensors based on intensity interrogation while presenting a significantly smaller footprint. The analyzed device is therefore a promising microcomponent for use in lab-on-a-chip biosensing platforms based on Si-based integrated optics. 


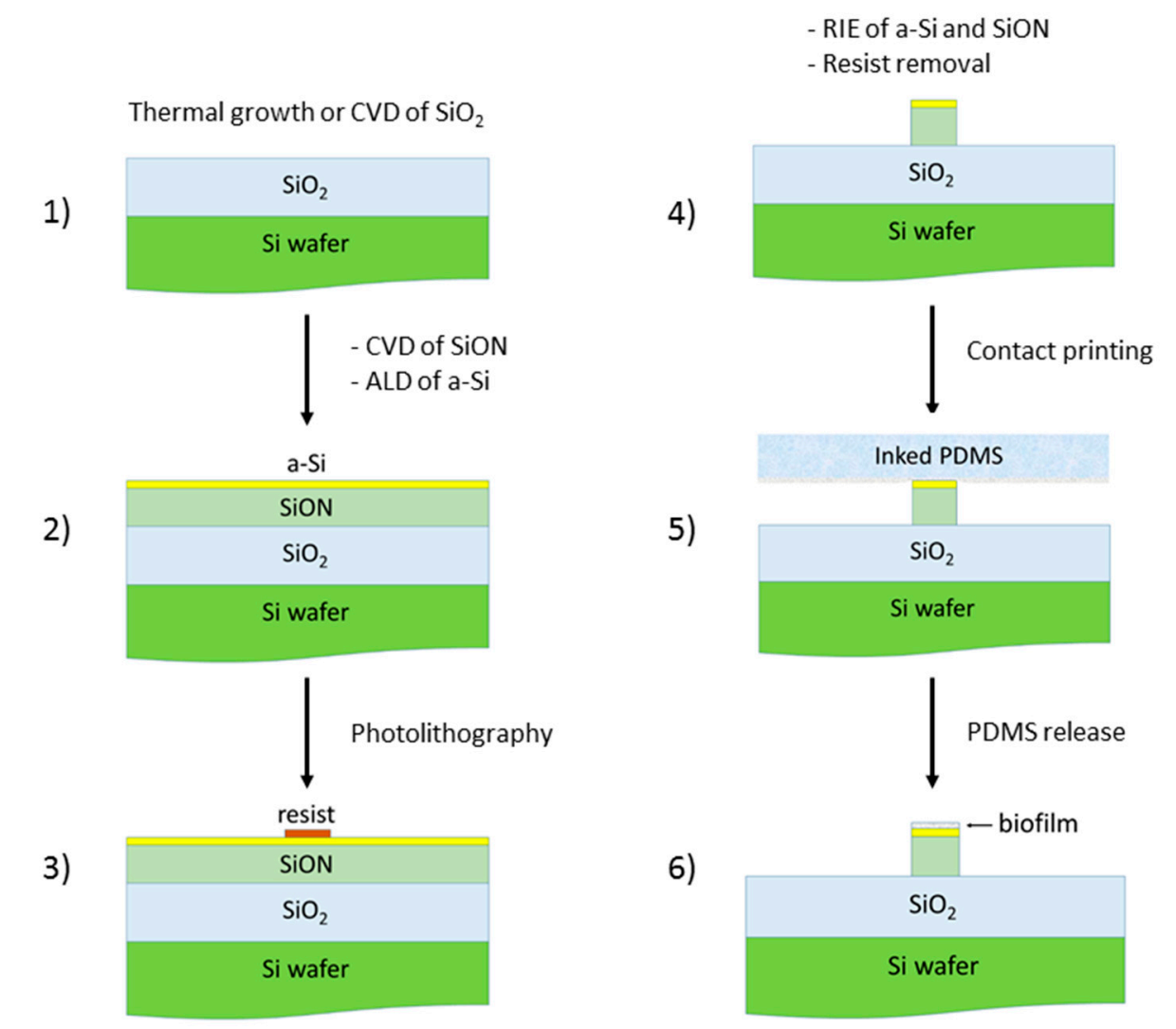

Figure 9. Schematic diagram of the main processing steps involved in the fabrication of the proposed integrated optical biosensor. Chemical vapor deposition (CVD); reactive ion etching (RIE); atomic layer deposition (ALD); polydimethylsiloxane (PDMS).

Funding: This research was funded by the Spanish Ministry "Ministerio de Economía y Competitividad" under project HERON (Ref.: TEC 2017-84846-R).

Conflicts of Interest: The author declares no conflict of interest.

\section{References}

1. Zinoviev, K.; Carrascosa, L.G.; del Río, J.S.; Sepúlveda, B.; Domínguez, C.; Lechuga, L.M. Silicon photonic biosensors for lab-on-a-chip applications. Adv. Opt. Technol. 2008, 2008, 1-6. [CrossRef]

2. Washburn, A.L.; Bailey, R.C. Photonics-on-a-chip: Recent advances in integrated waveguides as enabling detection elements for real-world, lab-on-a-chip biosensing applications. Analyst 2011, 136, 227-236. [CrossRef] [PubMed]

3. Gavela, A.F.; García, D.G.; Ramirez, J.C.; Lechuga, L.M. Last advances in silicon-based optical biosensors. Sensors 2016, 16, 285. [CrossRef] [PubMed]

4. Luan, E.; Shoman, H.; Ratner, D.M.; Cheung, K.C.; Chrostowski, L. Silicon Photonic Biosensors Using Label-Free Detection. Sensors 2018, 18, 3519. [CrossRef] [PubMed]

5. Heideman, R.G.; Kooyman, R.P.H.; Greve, J. Performance of a highly sensitive optical waveguide Mach-Zehnder interferometer immunosensor. Sens. Actuators B 1993, 10, 209-217. [CrossRef]

6. Weisser, M.; Tovar, G.; Mittler-Neher, S.; Knoll, W.; Brosinger, F.; Freimuth, H.; Lacher, M.; Ehrfeld, W. Specific bio-recognition reactions observed with an integrated Mach-Zehnder interferometer. Biosens. Bioelectron. 1999, 14, 405-411. [CrossRef]

7. Schipper, E.; Brugman, A.; Dominguez, C.; Lechuga, L.; Kooyman, R.; Greve, J. The realization of an integrated Mach-Zehnder waveguide immunosensor in silicon technology. Sens. Actuators B Chem. 1997, 40, 147-153. [CrossRef] 
8. Liu, Q.; Tu, X.; Kim, K.W.; Kee, J.S.; Shin, Y.; Han, K.; Yoon, Y.; Lo, G.; Park, M.K. Highly sensitive Mach-Zehnder interferometer biosensor based on silicon nitride slot waveguide. Sens. Actuators B Chem. 2013, 188, 681-688. [CrossRef]

9. Brandenburg, A. Differential refractometry by an integrated-optical Young interferometer. Sens. Actuators B Chem. 1997, 39, 266-271. [CrossRef]

10. Brandenburg, A.; Krauter, R.; Künzel, C.; Stefan, M.; Schulte, H. Interferometric sensor for detection of surface-bound bioreactions. Appl. Opt. 2000, 39, 6396-6405. [CrossRef]

11. Zinoviev, K.E.; González-Guerrero, A.B.; Domínguez, C.; Lechuga, L.M. Integrated bimodal waveguide interferometric biosensor for label-free analysis. J. Lightwave Technol. 2011, 29, 1926-1930. [CrossRef]

12. Krioukov, E.; Klunder, D.J.; Driessen, A.; Greve, J.; Otto, C. Sensor based on an integrated optical microcavity. Opt. Lett. 2002, 27, 512-514. [CrossRef] [PubMed]

13. Yalçin, A.; Popat, K.C.; Aldridge, J.C.; Desai, T.A.; Hryniewicz, J.; Chbouki, N.; Little, B.E.; King, O.; Van, V.; $\mathrm{Chu}, \mathrm{S}$.; et al. Optical sensing of biomolecules using microring resonators. IEEE J. Sel. Top. Quantum Electron. 2006, 12, 148-155. [CrossRef]

14. De Vos, K.; Bartolozzi, I.; Schacht, E.; Bienstman, P.; Baets, R. Silicon-on-Insulator microring resonator for sensitive and label-free biosensing. Opt. Express 2007, 15, 7610-7615. [CrossRef]

15. Barrios, C.A.; Bañuls, M.J.; Gonzalez-Pedro, V.; Gylfason, K.B.; Sánchez, B.; Griol, A.; Maquieira, A.; Sohlström, H.; Holgado, M.; Casquel, R. Label-free optical biosensing with slot waveguides. Opt. Lett. 2008, 33, 708-710. [CrossRef] [PubMed]

16. Lee, M.; Fauchet, P.M. Two-dimensional silicon photonic crystal based biosensing platform for protein detection. Opt. Express 2007, 15, 4530-4535. [CrossRef]

17. Scullion, M.G.; Falco, A.D.; Krauss, T.F. Slotted photonic crystal cavities with integrated microfluidics for biosensing applications. Biosens. Bioelectron. 2011, 27, 101-105. [CrossRef]

18. Carson, R.F. Periodic Coupling in Semiconductor-Clad Dielectric Optical Guided-Wave Devices. Ph.D. Thesis, The University of Virginia, Charlottesville, VA, USA, 1985.

19. Carson, R.F.; Batchman, T.E. Multimode phenomena in semiconductor-clad dielectric optical waveguide structures. Appl. Opt. 1990, 19, 2769-2780.

20. Kaminow, I.P.; Mammel, W.L.; Weber, H.P. Metal-Clad Optical Waveguides: Analytical and Experimental Study. Appl. Opt. 1974, 13, 396. [CrossRef]

21. Rashliegh, S.C. Planar Metal-Clad Dielectric Optical Waveguides. Ph.D. Thesis, The University of Queensland, Brisbane, Australia, May 1975.

22. Slavik, R.; Homola, J.; Ctyroky, J.; Brynda, E. Novel spectral fiber optic sensor based on surface plasmon resonance. Sens. Actuators B 2001, 74, 106-111. [CrossRef]

23. Zourob, M.; Goddard, N.J. Metal clad leaky waveguides for chemical and biosensing applications. Biosens. Bioelectron. 2005, 20, 1718-1727. [CrossRef] [PubMed]

24. Skivesen, N.; Horvath, R.; Thinggaard, S.; Larsen, N.B.; Pedersen, H.C. Deep-probe metal-clad waveguide biosensors. Biosens. Bioelectron. 2007, 22, 1282-1288. [CrossRef] [PubMed]

25. Andreev, A.; Pantchev, B.; Danesh, P.; Zafirova, B.; Karakoleva, E.; Vlaikova, E.; Alipieva, E. A refractometric sensor using index-sensitive mode resonance between single-mode fiber and thin film amorphous silicon waveguide. Sens. Actuators B 2005, 106, 484-488. [CrossRef]

26. Socorro, A.B.; Corres, J.M.; Del Villar, I.; Arregui, F.J.; Matias, I.R. Fiber-optic biosensor based on lossy mode resonances. Sens. Actuators B 2012, 174, 263-269. [CrossRef]

27. Paliwal, N.; John, J. Lossy Mode Resonance (LMR) Based Fiber Optic Sensors: A Review. IEEE Sens. J. 2015, 15, 5367-5371. [CrossRef]

28. Del Villar, I.; Arregui, F.J.; Zamarreño, C.R.; Corres, J.M.; Bariain, C.; Goicoechea, J.; Elosua, C.; Hernaez, M.; Rivero, P.J.; Socorro, A.B.; et al. Optical sensors based on lossy-mode resonances. Sens. Actuators B 2017, 240, 174-185. [CrossRef]

29. Pierce, D.T.; Spicer, W.E. Electronic Structure of Amorphous Si from Photoemission and Optical Studies. Phys. Rev. B 1972, 5, 3017-3029. [CrossRef]

30. Bossi, D.E.; Hammer, J.M.; Shaw, J.M. Optical properties of silicon oxynitride dielectric waveguides. Appl. Opt. 1987, 26, 609-611. [CrossRef]

31. Vorös, J. The density and refractive index of adsorbing protein layers. Biophys. J. 2004, 87, 553-561. [CrossRef] 
32. Rsoft Photonic Device Tools. Available online: https://www.synopsys.com/photonic-solutions/rsoft-photonicdevice-tools.html (accessed on 9 April 2020).

33. Perera, C.; Vernon, K.; Cheng, E.; Sathian, J.; Jaatinen, E.; Davis, T. Highly compact refractive index sensor based on stripe waveguides for lab-on-a-chip sensing applications. Beilstein J. Nanotechnol. 2016, 7, 751-757. [CrossRef]

34. Rodionov, S.A.; Remnev, M.A.; Klimov, V.V. Refractive index sensor based on all-dielectric gradient metasurface. Sens. Bio-Sens. Res. 2019, 22, 100263. [CrossRef]

35. Takashima, Y.; Kusaba, K.; Haraguchi, M.; Naoi, Y. Highly sensitive refractive index sensor using dual resonance in subwavelength grating/waveguide with normally incident optical geometry. IEEE Sens. J. 2019, 19, 6147-6153. [CrossRef]

36. Shakoor, A.; Grande, M.; Grant, J.; Cumming, D.R.S. One dimensional silicon nitride grating refractive index sensor suitable for integration with CMOS detectors. IEEE Photonics J. 2017, 9, 6800711.

37. Dahlin, A.B. Plasmonic Sensors: An Integrated View of Refractometric Detection; IOS Press: Amsterdam, The Netherlands, 2012. [CrossRef]

38. Lin, V.S.-Y.; Motesharei, K.; Dancil, K.-P.S.; Sailor, M.J.; Ghadiri, M.R. A porous silicon-based optical interferometric biosensor. Science 1997, 278, 840-843. [CrossRef]

39. Imai, S.; Iizuka, T.; Sugiura, O.; Matsumura, M. Atomic layer epitaxy of Si using atomic H. Thin Solid Films 1993, 225, 168-172. [CrossRef]

40. Hasunuma, E.; Sugahara, S.; Hoshino, S.; Imai, S.; Ikeda, K.; Matsumura, M. Gas-phase-reaction-controlled atomic-layer-epitaxy of silicon. J. Vac. Sci. Technol. A 1998, 16, 679-684. [CrossRef]

41. Ikeda, K.; Yanase, J.; Sugahara, S.; Matsumura, M. Atomic-Layer-Epitaxy of Si. J. Korean Phys. Soc. 2001, 39, S447-S458.

42. Bernard, A.; Renault, J.P.; Michel, B.; Bosshard, H.R.; Delamarche, E. Microcontact printing of proteins. Adv. Mater. 2000, 12, 1067-1070. [CrossRef]

43. LaGraff, J.R.; Chu-LaGraff, Q. Scanning force microscopy and fluorescence microscopy of microcontact printed antibodies and antibody fragments. Langmuir 2006, 22, 4685-4693. [CrossRef]

(C) 2020 by the author. Licensee MDPI, Basel, Switzerland. This article is an open access article distributed under the terms and conditions of the Creative Commons Attribution (CC BY) license (http://creativecommons.org/licenses/by/4.0/). 